\title{
Feline ceruminous cystomatosis pada kucing persia 7 tahun
}

\author{
Siti Zaenab ${ }^{1}$, Osye Alamsari ${ }^{1}$, Kemala Sherlin ${ }^{1}$, Benda Alifianti ${ }^{1}$, \\ Belinda Martin ${ }^{1}$, Fathia Ramadhani ${ }^{1,2} *$ \\ ${ }^{1}$ My Vets Animal Clinic, Jalan Kemang Selatan VIII No. 7A Bukit Kemang, Jakarta Selatan \\ ${ }^{2}$ Balai Besar Penelitian Veteriner, Jalan R.E. Martadinata No. 30, Ciwaringin, Bogor
}

ABSTRAK: Feline ceruminous cystomatosis (ceruminous adenoma, apocrine cystadenomatosis) adalah kelainan
nonneoplastik dan tidak umum yang terjadi pada kucing. Kucing Persia berusia 7 tahun datang ke My Vets Animal Clinic di
Kemang Selatan dengan keluhan ada kutil-kutil hitam di sepanjang kedua daun telinga. Tindakan bedah berupa pengangkatan
dipilih untuk menangani feline ceruminous cystomatosis tersebut dengan teknik ablasi saluran telinga vertikal sebagai pilihan.
Ablasi terhadap kista menggunakan laser karbon dioksida adalah metode penanganan yang lebih dipilih, namun tindakan
bedah berupa pengangkatan total pernah menjadi terapi pilihan. Hasil persembuhan luka jangka panjang pascabedah pada
feline ceruminous cystomatosis menunjukkan hasil yang cukup bagus.
Kata kunci:
apocrine cystadenomatosis, ceruminous adenoma, feline ceruminous cystomatosis, Persian, vertical ear canal ablation

\section{- PENDAHULUAN}

Feline ceruminous cystomatosis (ceruminous adenoma, apocrine cystadenomatosis) adalah kelainan non-neoplastik dan tidak umum terjadi pada kucing. Lesi umumnya terlihat pada bagian konkaf pinna, pembukaan saluran telinga bagian luar, dan di dalam saluran telinga. Predisposisi terjadi pada kucing Abyssinian dan Persian (Berger 2015).

\section{- KASUS DAN PEMBAHASAN}

Kucing Persia berusia 7 tahun datang ke My Vets Animal Clinic di Kemang Selatan Jakarta dengan keluhan ada kutilkutil hitam di sepanjang kedua daun telinga. Pemeriksaan fisik menunjukkan adanya vesikula dan/atau nodul bergerombol berwarna abu-abu gelap hingga hitam (Gambar 1). Temuan ini tampak sebagaimana pada kasus feline ceruminous cystomatosis. Secara klinis, feline ceruminous cystomatos tampak lesi yang menonjol dan terdiri dari sejumlah papul, vesikula, dan atau nodul berwarna abu-abu kebiruan atau ungu (Berger 2015).

Tindakan bedah berupa pengangkatan total dipilih untuk menangani feline ceruminous cystomatosis tersebut (Fossum dan Caplan 2017). Anastesi inhalasi digunakan sebagai maintenance anestesi. Teknik ablasi saluran telinga vertikal digunakan sebagai pilihan. Teknik ini dilakukan jika keseluruhan saluran vertikal terkena lesi, tetapi saluran horisontal masih normal (Fossum dan Caplan 2017). Pengangkatan total saluran vertikal akan menghasilkan nyeri dan eksudat lebih sedikit jika dibandingkan dengan teknik reseksi telinga lateral.

Kucing direbahkan pada posisi lateral recumbency dengan kepala disangga handuk agar lebih tinggi. Insisi berbentuk $\mathrm{T}$ dilakukan dengan komponen horisontal paralel dan tepat berada di bawah tepi atas tragus. Insisi vertikal dilakukan lagi dari titik tengah insisi horisontal hingga melewati permukaan saluran horizontal (Gambar 1).
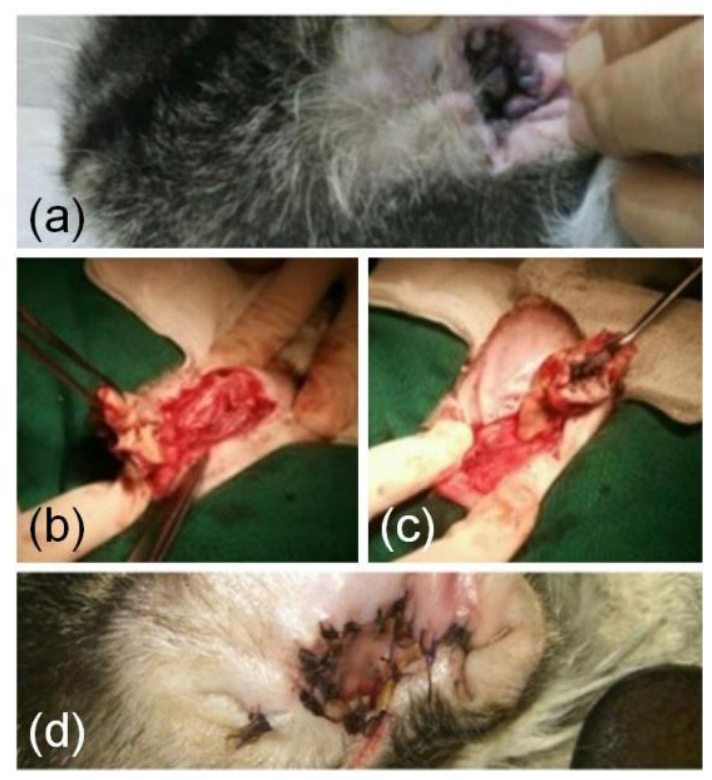

Gambar 1 Feline ceruminous cystomatosis pada kucing (a), proses vertical ear canal ablation (b-c), dan pascabedah (d).

Skin flap dan jaringan ikat yang kendur ditarik, dan aspek lateral saluran vertikal dibuka. Insisi horisontal dilakukan hingga kartilago sekeliling saluran telinga luar. Aspek proximal dan medial saluran telinga dipisahkan

Diterima: 10-11-2017 | Direvisi: 27-12-2017 | Disetujui: 03-04-2018 (C) 2018 CC-BY-SA. Ini adalah artikel Open Access yang didistribusikan berdasarkan ketentuan dari Creative Commons Attribution ShareAlike 4.0 International License (https://creativecommons.org/licenses/by-sa/4.0/). 
dengan gunting bengkok. Seluruh saluran vertikal dibersihkan dari muskulus atau fascia yang menempel. Saluran tersebut kemudian digunting sekitar 1-2 cm dan saluran yang digunting tersebut dapat digunakan untuk diperiksa histologi. Saluran vertikal yang tersisa diinsisi ke arah cranial dan kaudal untuk membuat flap dorsal dan ventral. Flap ventral ditarik dan dijahitkan ke kulit. Flap dorsal dijahitkan ke kulit dan jaringan subkutan ditutup. Kulit kemudian ditutup berbentuk T (Fossum dan Caplan 2017). Prosedur ini dilakukan pada kedua telinga. Saat ini, ablasi terhadap kista dilakukan menggunakan laser karbon dioksida sebagai metode treatment yang lebih dipilih, namun tindakan bedah berupa pengangkatan total juga pernah menjadi treatment pilihan (treatment of choice) (Berger 2015, Hnilica 2011).

Hari ketiga pascabedah, jahitan pada kedua telinga rapat, tidak ada perdarahan, bagian medial telinga kiri sedikit basah dan jahitan telinga kanan kering. Hari kelima pascabedah, jahitan telinga kiri mulai kering dan jahitan kedua telinga rapat. Hari keenam pascabedah, jahitan kedua telinga rapat, kering, dan tidak ada perdarahan. Kucing selalu dalam kondisi alert. Kucing diberikan analgesik dan antibiotik untuk 7 hari pascabedah. Telinga selalu dibersihkan dengan larutan salin fisiologis dan diberikan Genoint ${ }^{\circledR}$ (Erela) yang berisi gentamycin sulphate selama
18 hari pascabedah. Megaderm ${ }^{\circledR}$ (Virbac) yang berisi omega 3 dan omega 6 diberikan sebagai suplemen tambahan jangka panjang.

\section{— SIMPULAN}

Tindakan ablasi pada feline ceruminous cystomatosis jangka panjang menunjukkan hasil yang cukup bagus jika diikuti terapi yang tepat setelah tindakan bedah.

\section{- INFORMASI PENULIS}

Penulis untuk Korespondensi

*FR: ramadhani1129@gmail.com

Balai Besar Penelitian Veteriner,

Jalan R.E. Martadinata No. 30, Ciwaringin, Bogor

\section{- PUSTAKA ACUAN}

Berger D. 2015. Feline Ceruminous Cystomatosis. Clinician's Brief. June, 2015: 25.

Fossum TW, Caplan ER. 2017. Surgery of the Ear. dalam Fossum TW, editor. Small Animal Surgery Fourth Edition. Missouri (US): Elsevier.

Hnilica KA. 2011. Small Animal Dermatology: A Color Atlas and Therapeutic Guide. Missouri (US): Elsevier. 